\title{
Getting the Mix Right Again: An updated and theoretical rationale for interaction
}

\author{
Terry Anderson \\ Athabasca University - Canada’s Open University
}

No topic raises more contentious debate among educators than the role of interaction as a crucial component of the education process. This debate is fueled by surface problems of definition and vested interests of professional educators, but is more deeply marked by epistemological assumptions relative to the role of humans and human interaction in education and learning. The seminal article by Daniel and Marquis (1979) challenged distance educators to get the mixture right between independent study and interactive learning strategies and activities. They quite rightly pointed out that these two primary forms of education have differing economic, pedagogical, and social characteristics, and that we are unlikely to find a "perfect" mix that meets all learner and institutional needs across all curricula and content. Nonetheless, hard decisions have to be made.

Even more than in 1979, the development of newer, cost effective technologies and the nearly ubiquitous (in developed countries) Net-based telecommunications system is transforming, at least, the cost and access implications of getting the mix right. Further, developments in social cognitive based learning theories are providing increased evidence of the importance of collaborative activity as a component of all forms of education - including those delivered at a distance. Finally, the context in which distance education is developed and delivered is changing in response to the capacity of the semantic Web (Berners-Lee, 1999) to support interaction, not only amongst humans, but also between and among autonomous agents and human beings.

Thus, the landscape and challenges of "getting the mix right" have not lessened in the past 25 years, and, in fact, have become even more complicated. This paper attempts to provide a theoretical rationale and guide for instructional designers and teachers interested in developing

distance education systems that are both effective and efficient in meeting diverse student learning needs.

\section{Defining and Valuing Interaction in Distance Education}

Interaction has long been a defining and critical component of the educational process and context. Yet it is surprisingly difficult to find a clear and precise definition of this multifaceted concept in the education literature. In popular culture, the use of the term to describe everything from toasters to video games to holiday resorts, further confuses precise definition. I have discussed these varying definitions at greater length in an earlier document (Anderson, 2003), and so will confine discussion here to an acceptance of Wagner's (1994) definition as "reciprocal events that require at least two objects and two actions. Interactions occur when these objects and 
events mutually influence one another” (p. 8). This definition departs from Daniel and Marquis's stipulation that interaction should refer "in a restrictive manner to cover only those activities where the student is in two-way contact with another person (or persons)" (Daniel and Marquis, 1988, p. 339). As was articulated by Moore (1989), and Juler (1990), and as I too will argue, interaction between students and content has long been recognized as a critical component of both campus-based and distance education.

Interaction (or its derivative term interactivity) serves a variety of functions in the educational transaction. Sims (1999) has listed these functions as allowing for learner control, facilitating program adaptation based on learner input, allowing various forms of participation and communication, and as aiding the development of meaningful learning. In addition, interactivity is fundamental to creation of the learning communities espoused by Lipman (1991), Wenger (2001), and other educational theorists who focus on the critical role of community in learning. Finally, the value of another person's perspective, usually gained through interaction, is a key learning component in constructivist learning theories (Jonassen, 1991), and in inducing mindfulness in learners (Langer, 1989).

Interaction has always been valued in education. As long ago as 1916, John Dewey referred to a form of internal interaction as the defining component of the educational process that occurs when the student transforms the inert information passed to them from another, and constructs it into knowledge with personal application and value (Dewey, 1916). Later, from a distance education perspective, Holmberg (1989) argued for the superiority of individualized interaction between student and tutor when supported by written postal correspondence or via real time telephone tutoring. Holmberg also introduced us to the idea of simulated interaction that defines the writing style appropriate for independent study models of distance education programming, which he referred to as "guided didactic interaction." Garrison and Shale (1990) defined all forms of education (including that delivered at a distance) as essentially interactions between content, students, and teachers. Laurillard (1997) constructed an ideal conversational model of learning applicable to all forms of education in which interaction between students and teachers plays the critical role. Finally, Bates (1990) argued that interactivity should be the primary criteria for selecting media for educational delivery. Thus, there is a long history of study and recognition of the critical role of interaction in supporting and even defining education.

\section{Interaction and Education}

Despite the functional definitions of interaction listed above, it still remains a challenge to define when an interaction has pedagogical or educational value. Certainly not all interactions have formal educational value as illustrated by light social conversation in a pub, or the prescribed interaction between a pilot and an air-traffic controller. However, even those two examples can be the context in which informal learning by either or both parties occurs. For the purposes of this paper, I will distinguish between interaction leading to learning in any informal context and those types of interaction that occur in a formal education context. Informal interaction can, and often does, lead to learning outside of any influence of a formal education institution or accreditation process. However, interaction in formal education contexts is specifically designed to induce learning directed towards defined and shared learning objectives or outcomes. Interaction with a teacher is often an important component of a formal learning experience. However, since both formal and informal learning can result from interaction between and amongst students alone, or as result of interaction between student and content, the participation of a teacher cannot be a defining feature of an educational interaction. Further, it is obvious that there are qualitative differences in the quality and value of interaction as a contributor to learning in both formal and 
informal learning contexts. To simplify the arguments presented in this paper, I have not addressed these qualitative differences, although remind the reader that all types of interaction should be assessed by their contribution to the learning process.

\section{Modes of Interaction}

Anderson and Garrison (1998) described the three more common types of interaction discussed in the distance education literature involving students (student-student; student-teacher; studentcontent), and extended the discussion to the other three types of interaction (teacher-teacher; teacher-content; content-content) as shown in Figure 1. In Anderson (2003), I discussed the various costs, benefits, and research questions associated with each of these modes of interaction. I also suggested that due to the increasing computational power and storage capacity of computers (Moore's Law), their increase in functionality when networked (Metcalfe's Law), and related geometric increases in a host of technical developments (Kurzweil, 1999), there is pressure and opportunity to transform student-teacher and student-student interaction into enhanced forms of student-content interaction. Further, the development of programming tools and environments will continue to make this transformation easier and, in some cases, within the technical domain of non-programming teachers and subject matter experts. However, I have not clearly articulated a theoretical basis for judging the appropriate amounts of each of the various forms of possible interaction.

Figure 1. Modes of Interaction in Distance Education from Anderson and Garrison, (1998).

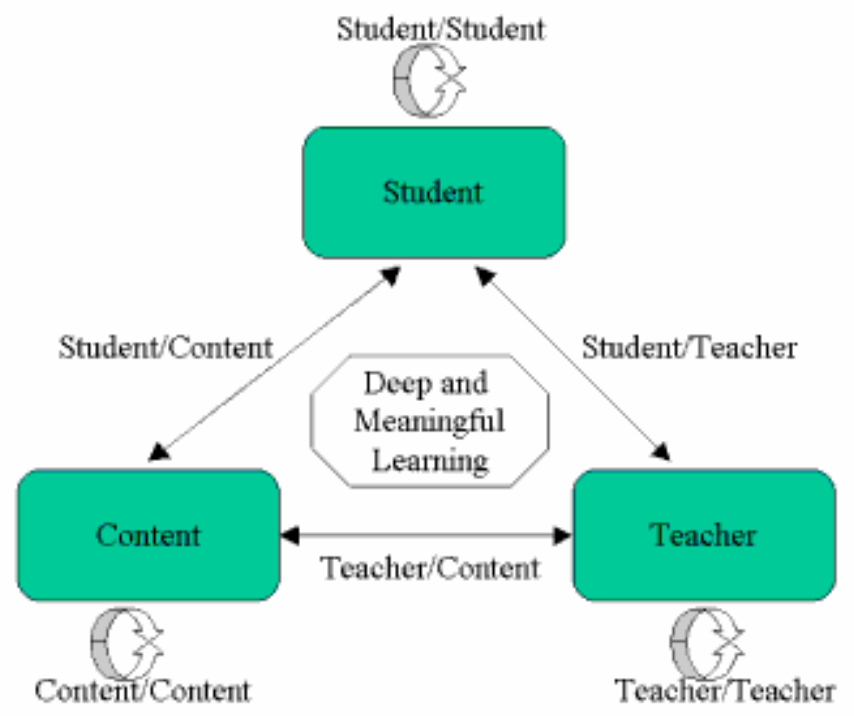

\section{Equivalency of Interaction}

After years of sometimes acrimonious debate, it seems clear that there is no single medium that supports the educational experience in a manner that is superior in all ways to that supported via other media. Clark's (1994) and Kozma's (1994) classic debate, and the long list of "no significant difference” studies compiled by Russell (2000), give evidence to a complicated interaction between content, student preference and need, institutional capacity and preference, 
and teaching and learning approaches to learning. Despite the high degree of rhetoric from constructivist and feminist educational theorists of the value of interaction in creating interdependence in the learning sequence (Kirkup and von Prummer, 1990; Litzinger, Carr and Marra, 1997), there is also evidence that many students deliberately choose learning programs that allow them to minimize the amount of student-teacher and student-student interaction required (May, 2003; Kramarae, 2003). Over the years, in my own distance teaching, I have been informally polling students about the relative advantage and disadvantage of various forms of mediated and face-to-face, synchronous and asynchronous, educational activities. From these polls, I conclude that there is a wide range of need and preference for different combinations of paced and un-paced, synchronous and asynchronous activity, and also a strong desire for variety and exposure to different modes and modularities of educational provision and activity.

From these observations and from the literature debate, I have developed an equivalency theorem as follows.

Deep and meaningful formal learning is supported as long as one of the three forms of interaction (student-teacher; student-student; student-content) is at a high level. The other two may be offered at minimal levels, or even eliminated, without degrading the educational experience.

High levels of more than one of these three modes will likely provide a more satisfying educational experience, though these experiences may not be as cost or time effective as less interactive learning sequences.

This theorem implies that an instructional designer can substitute one type of interaction for one of the others (at the same level) with little loss in educational effectiveness - thus the label of an equivalency theory. There are a number of other corollaries and implications based on the current post-industrial education context that can be drawn from this theorem, and I have attempted to provide a start at this process in the following lists.

\section{Student Interaction}

- Quality educational programming requires high levels of interaction by students in at least one area, and can substitute for minimal to no interaction in the other two.

- Student-teacher interaction currently has the highest perceived value amongst students, and thus commands highest market value.

- Some student-teacher interactions can be automated, and thus substituted in whole or part, through the development and use of content resources, and especially those utilizing autonomous teacher agents. This practice migrates Net based forms of student-teacher interaction (emails, conferencing discussion, etc.) to student-content interactions (teacher videos, virtual labs, personalized FAQs, etc.).

- Most forms of student-content interaction can be recorded and displayed asynchronously to substitute for student-student interaction by time or technology bound students.

- Student-student interaction is critical for learning designs based upon constructivist learning theories, but less critical to cognitive and behaviorist learning theory based approaches. 
- Student-student interaction is critical for skill proficiency needed for collaborative or cooperative tasks. Thus, most effective learning to reach these goals maximizes studentstudent interaction.

- Student-content interaction is most accessible, and most readily adapted, via individualized "student portfolios," that can influence design, assessment, or delivery customizations (mass customization).

\section{Teacher Interaction}

- Traditional approaches to teaching of each discipline, biases teachers towards different mixes of interaction.

- Teacher-student interaction is generally the least scaleable type of interaction, and thus is usually substituted for by student-content interaction in mass education systems.

- Teacher agents can perform many of the functions that currently consume teacher time, especially those of a bookkeeping, clerical, or organizational nature, thus migrating teacher-student and teacher-content interaction to content-student and content-content interaction.

- Some teacher interaction can be transformed into learning objects (videos, animations, assessment programs etc.), thus migrating student-teacher interaction to student-content interaction.

- As professional students of their discipline, teachers, need professional development and knowledge building opportunities throughout their careers. Deep and meaningful learning to a professional, requires high levels of interaction in at least one of teacher-teacher; teacher-learner; teacher-content domains. High levels of one, allow for reductions in the other two.

- Teacher-teacher collaboration is critical to the current model of university based research production and evaluation.

\section{Content Interaction}

- Content, having only volition ascribed to it by humans, is the most flexible of actors, "willing" to undertake any combination and quantity of interaction.

- The cost and restrictions on value of content interaction is falling much faster than interaction involving the other two forms of interaction (Moore's and Metcalfe's Laws), and thus is expanding in all areas, putting a premium value and cost on human based interaction: student-student, student-teacher, and teacher-teacher.

- The semantic Web (Berners-Lee, 1998) provides an environment in which content can be formalized and manipulated, stored, searched, and computed automatically through autonomous agent technologies. Such capacity will allow development of much more useful teacher and learner agents, encouraging migration to content-based forms of interaction. 
- The value of the content is dependent on the extent to which it engages students or teachers in interaction, leading to relevant knowledge construction. There is also a direct relationship between this capacity for interaction and resulting engagement, mindfulness, and motivation.

\section{Assessing the Level of Interactivity}

Differentiating between high and low levels of interactivity is largely a quantitative exercise in which a researcher, developer, or the participants themselves, count the number of times they are actively engaged with the other participants or content. There is some evidence to suggest value in "vicarious interaction," in which non-active participants gain from observing and empathizing with active participants (Sutton, 2001; Fulford and Zhang, 1993). However, high levels of interaction generally require the actors to be personally active and engaged in the interaction. Although there will be qualitative differences in the extent of individual involvement in the interaction, these differences are largely individualized and difficult to prescribe or assess across the large numbers of participants typically found in current education systems. Thus, for planning or development purposes, designers are encouraged to build into their programs strategic amounts of each type of interaction, and to develop activities that will encourage this amount of interaction.

\section{Examples of Applying the Equivalency Theorem to Popular Education Delivery Modes}

The following examples illustrate the operation of the equivalency theorem in most common forms of campus and distance delivered education systems.

\section{Classroom Delivery}

The traditional lecture mode of delivery has medium levels of student-teacher interaction, usually low levels of student-student interaction, and medium to low levels of student-content interaction. For these reasons, I am not alone in critiquing the lecture format (Garrison, 2000), and note its historical genesis in being read to from scarce content (hand-scribed books). Its value in an era of ubiquitous content is thus reduced. Recent efforts at enhancing lecture theatres through use of multimedia equipment, and especially enabling access to net resources in "smart classrooms," will increase the quality of student-content interaction, and thus the potential to increase levels of deep and meaningful learning.

Efforts at enhancing teacher-student interaction through an increase in teacher immediacy (McCrosky and Richmond, 1992), or through use of theatrical or multimedia presentation techniques, can also be expected to increase the quality of student-teacher interaction. Further efforts at enhancing student-student interaction in the classroom through case or problem based learning activities, have long been shown to increase not only student achievement, but also student completion and enjoyment rates (Slavin, 1995). In these types of activities, increased student-student interaction is substituting for student-teacher interaction.

When classroom delivery takes the form of a traditional seminar among relatively small numbers of students and a teacher, the levels of student-student and student-teacher interaction increase with generally increased levels of learning and satisfaction. Access to "smart classroom" 
technologies is generally less necessary in seminars, as high levels of learning are already being achieved through high levels of student-student and student-teacher interaction.

\section{Traditional Distance Education Delivered via Mail or Electronic Correspondence}

In this mode, specially designed independent study materials are constructed with the explicit intent of providing high levels of student-content interaction. As noted, attention to the creation of a personal voice in the content, and attention to ways to create "guided didactic interaction" in the text materials, can create high levels of student-content interaction. In more recent times, independent study materials have been delivered electronically and enhanced through addition of java applets, automated testing, and quiz forms of feedback, simulations, adaptive computer assisted instruction, and other applications of "learning objects." Each of these technologies enhances student-content interaction and thus, if well designed and applied appropriately, is likely to enhance the learning experience. Student-teacher interaction is possible in independent study, but generally does not happen to a great extent with the majority of learners (Coldeway, 1991). Rather, efforts are made to create study paths that allow students to learn with minimal amounts of interaction with the teacher, other than to provide occasional formative and definite summative student assessment. Student-student interaction is also usually minimized allowing for maximum flexibility, start and finish times for courses, and capacity for students to set their own pace through the learning content. Thus, independent study provides high levels of learning by maximizing student-content interaction, and getting away with minimal amounts of studentteacher and student-student interaction.

Having stated that student-teacher interaction is generally low, there are ways in which it can be expanded in a cost effective manner. In particular, the call centre system developed at Athabasca University allows students extended access (7 days a week, 12 hours a day) to call centre staff who are equipped with frequently asked question databases, course syllabi, and a limited amount of content knowledge to answer a wide variety of student inquiries in timely fashion. Adria and Woudstra (2001) report that over 80 per cent of questions and concerns from over 11,000 registered students are handled successfully by call centre staff, thereby reducing the cost of administration related student-teacher interaction, and allowing more time for high quality academic interaction.

\section{Audio and Video Conferencing}

Audio and video conferencing provide slightly less accessible and 'leaner' interaction between and amongst teachers and students, due to the inherent technological distance between students and teachers imposed by the mediating technology. There is a further reduction in paralinguistic clues in audio teleconferencing as opposed to video conferencing, so that, in sum, there are only medium levels of student-teacher interaction. Student-content interaction is also at medium levels - if the conferences are enhanced with graphics or Net cruising capability as is supported in many of the new Internet-based conferencing systems now appearing on the market. High levels of student-student interaction are possible and, indeed, this level is the mantra of proponents of synchronous conferencing education systems (Roberts, 1998; Parker and Olgren, 1980). However, there is much anecdotal and some empirical evidence (Kirby and Boak, 1987) that teachers often use the media almost exclusively for delivery of lectures. If the conference is designed to support high levels of student-student interaction, then there is high potential for high levels of learning. I have been particularly struck by the differences in the amount and intensity of 
student-student interaction, as delivery of video and audio conferencing has moved from the dedicated learning center to the home or workplace. We documented the extent of 'side-talk' student-student interaction in the learning center that was not shared with other sites or the teacher. We found that in more than half of the time, these student-student interactions were both on track and conducive to learning (Anderson and Garrison, 1995). Now, as we progress to delivery directly to individual homes and offices, I notice a drop off of student-student interaction as the side-talk channel is reduced or eliminated, and the distractions of home life or alluring availability of Web surfing and email, increase the challenge of engaging students in studentstudent or student-teacher interaction.

\section{Web-based Courses}

The current stampede of educational institutions to mount and deliver "Web courses" has given rise to a large variation of models and modes of delivery. All use the Web differently, making categorization difficult. Web-based courses delivered using audio or video graphic systems such as Centra or E-Luminate share the same technical and pedagogical strengths and weaknesses of earlier video and audio-graphic systems. Canned streaming video lectures share more characteristics with the delivery classroom in which they were captured, than more radical forms of instructional design that the Web is capable of supporting. Earlier forms of computer assisted instruction are now being ported to the Web, thus reducing the inconvenience and cost of burning and distributing CDs, while retaining most of the pedagogical characteristics of their earlier instructional format.

The most common, and currently most pedagogically attractive, forms of Web delivery described in the literature are those based upon extensive use of text based computer mediated communications. In our content analysis studies of transcripts of these interactions (see papers by Anderson, Garrison, Archer, and Rourke, 1999; 2000 at: http://www.atl.ualberta.ca/cmc/), we have shown how creation of adequate levels of cognitive, social, and teaching presence are associated with high levels of deep and meaningful learning. This form of distance delivery places a premium on quality student-student interaction that is supported in a format that allows for asynchronous reflection and scholarly expression in text format. This high level of studentstudent interaction capacity allows for reduced student-teacher interaction, the capacity to make effective use of peer moderators (Rourke and Anderson, 2002), and facilitates students sharing and discussing student-content learning resources gathered or created by students (Collis and Moonen, 2001).

I am also impressed with the capacity of the Web to support enhanced levels of content interaction, and for autonomous agents to be created to assist both teachers and students in the educational process. For example, work by the Open Digital Markup Language defines "an extensible language and vocabulary (data dictionary) for the expression of terms and conditions over any content including permissions, constraints, obligations, conditions, and offers and agreements with rights holders”(ODRL, 2002, website at: http://www.odrl.net/). ODRL can thus be configured to allow content itself control, monitor, and manage access to it by students and teachers. An excellent example of the use of student agents is the I-Help system developed by Jim Greer and his colleagues at the University of Saskatchewan (Greer et al., 2001). This system allows each student to create an agent that seeks out and negotiates with other student agents for personalized assistance and help (provided by email by other students). The system selects and values previous student assistance, finds those students who are most available and most knowledgeable, and negotiates a fee for services rendered. Thus, the system is stimulating and 
tracking student-student interaction, allowing less dependence on student-teacher or studentcontent interaction as predicted by my equivalence theorem.

\section{An Interaction-based Model of e-Learning}

This interaction theorem leads us to view education as resulting from the creation of opportunities for each of the three major actors to interact with each other. This interaction is modeled in Figure 2.

Figure 2. A Model of Online learning

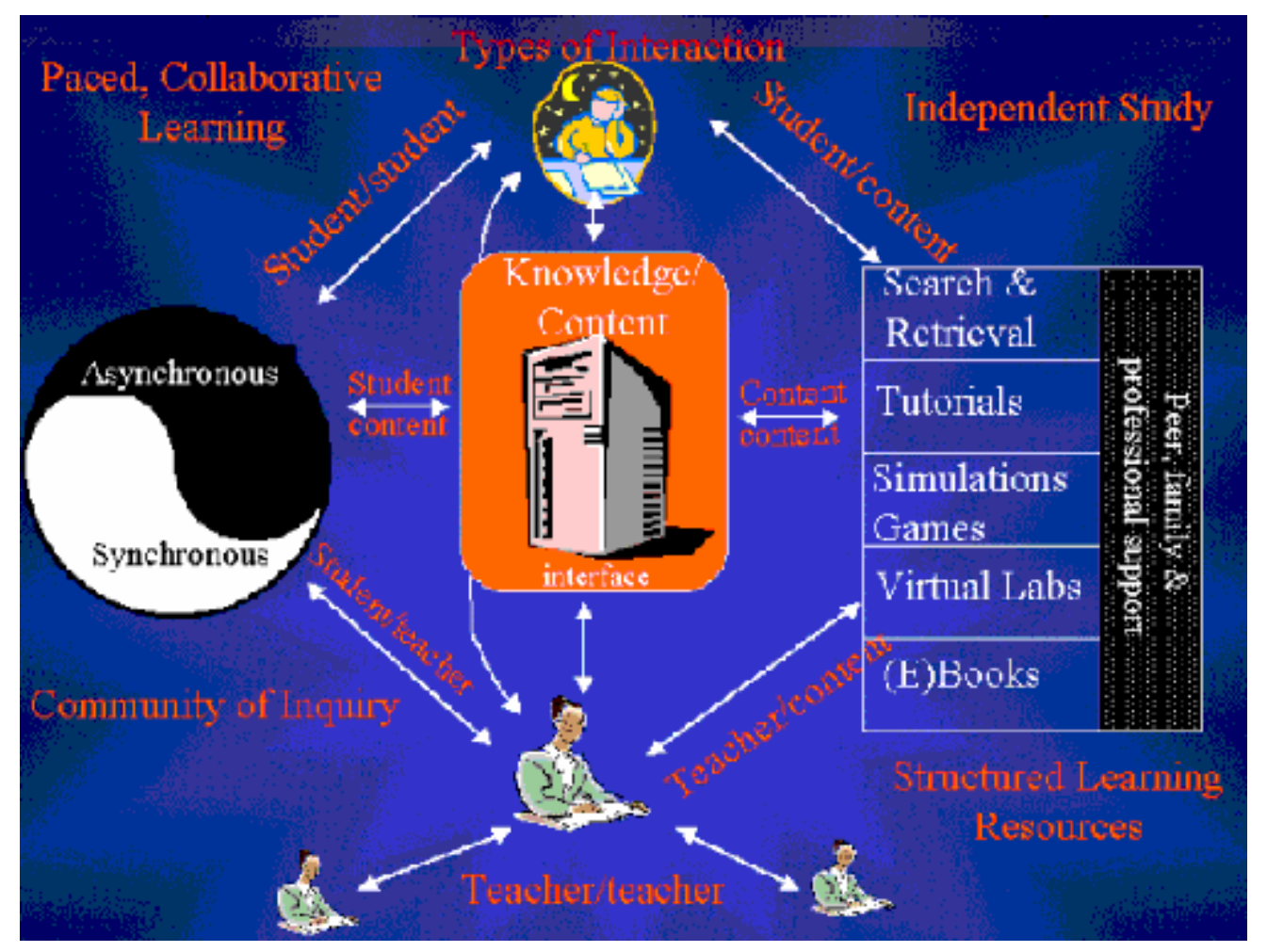

The model in Figure 2 illustrates the two major human actors - learners and teachers, and their interactions with each other and with content. Learners can, of course, interact directly with content that they find in multiple formats, and especially on the Web, however many choose to have their learning sequenced, directed, and credentialed through the assistance of a teacher. This interaction can take place within a community of inquiry (left side of Figure 2) using a variety of Net-based synchronous and asynchronous (video, audio, computer conferencing, chats, or virtual world) interaction. These environments are particularly rich and encourage the development of social skills, collaborative learning, and the development of personal relationships amongst participants as components of the learning process. However, the community binds learners in time, forcing regularly sessions or at least group paced learning. Community models are also generally more expensive as they suffer from an inability to scale to large numbers of learners. For example, many proponents of computer conferencing based learning place a practical limit less than 30 students per teacher facilitated class (Turoff, 1997). A second model of learning (on the right of Figure 2) illustrates the learning tools and activities associated with independent learning. Common tools used in this mode include computer assisted learning tutorials, drills, synthesis of content retrieved from the Net and simulations. Virtual labs in which students 
complete simulations of lab experiments, and sophisticated search and retrieval tools, are also becoming common tools for learning individually. Texts in either print (and now distributed and read online) have long been used as the basis for conveying teacher interpretations and insights into knowledge in independent study. However, it should also be emphasized, that although engaged in independent study, the independent study student is not alone. Often colleagues in the workplace, peers located locally or distributed across the Net, and family, have been shown to be significant sources of support and assistance to independent study learners (Potter, 1998).

The model helps instantiate the interaction theory by showing a sample of particular technologies and learning activities that a designer or teacher selects when developing an effective course or learning sequence.

\section{Conclusion}

The equivalency theorem proposed in this paper is not as complicated nor as technically detailed as other theories relevant to distance education (e.g., Jaspers, 1991; Saba and Shearer, 1994). However, its simplicity allows it to function as an accessible heuristic for distance education delivery design. The role of theory in science, education, and particularly instructional design has been much discussed (Seels, 1997; Garrison, 2000) and is seen as multifaceted. My intent with this article has not been to generate "grand theory" that explains and predicts behavior in a system as complex as an educational interaction. Nor has it my intent to develop the type of logicodeductive theory valued in the natural sciences for their capacity to generate testable hypotheses. Rather, it has more in common with grounded theory investigation (Corbin and Strauss, 1990), in which researchers are urged to go beyond description of data to generate inferences about phenomena they encounter in order that both researchers and practitioners are better able to interpret their findings, and meaningfully and purposively change their practice.

Wilson (1997) described three functions that a good educational theory performs. First, it helps to envision new worlds. The interaction equivalency theorem illustrates our capacity to effectively substitute one form of interaction for another. Getting the mix right involves a series of tradeoffs, and knowing how one type of interaction can effectively substitute for another, provides an essential decision making skill in the distance educators' knowledge base. Second, a good theory helps us make things. As new communications technology are brought to market, they seek their place in the arsenal of available tools, propelled by often effusive praise of early adopters and salespersons with vested interests. This theory helps us to position them and make judgments as to their potential effectiveness and efficiency in program planning. Finally, Wilson argues that a good theory keeps us honest. I hope this small theoretical piece encourages dialogue within our community of practice. It challenges us to critically evaluate just how much of the educational process can be composed of interaction with non-human entities, and further, to consider how much of the human interaction should take place face-to-face or in real time. These questions are not easily answered, but such reflective discourse is critical to the growth of our discipline and individual practice. It is also apparent that this theorem is a developing work that will benefit from comments, critiques, and expansion by other researchers and distance education practitioners.

Many distance educators come to their profession with a profound commitment to humanize the distance education process through provision of effective student-teacher interaction. These educators are threatened by models of distance education that are designed to reduce cost and access, primarily by reducing or even eliminating student-teacher interaction. The theorem and model described in this paper provides examples of many types of effective distance education 
programming based upon a variety of types and mixes of interaction. I am convinced that many of these alternatives should be focused on creating the most cost effective and accessible alternatives that can scale to meet the burgeoning global demand for effective and affordable life long learning opportunities. In most cases, these models will drastically reduce the amount of teacher-student interaction, and substitute it with increased student-student and student-content interaction. For many, this scenario is a frightening one, but one that is in keeping with our tradition of expanding educational access and opportunity, and thus not one we should abhor.

\section{References}

Adria, M., and Woudstra, A. (2001). Who's on the line? Managing student communications in distance learning using a one-window approach. Open Learning, 16(3), 249 - 261.

Anderson, T., and Garrison, D. R. (1995). Transactional issues in distance education: The impact of design in audio teleconferencing. American Journal of Distance Education, 9(2), 27 45 .

Anderson, T., and Garrison, D.R. (1998). Learning in a networked world: New roles and responsibilities. In C. Gibson (Ed.), Distance Learners in Higher Education. (p. 97-112). Madison, WI.: Atwood Publishing.

Anderson, T. (2003). Modes of interaction in distance education: Recent developments and research questions. In M. Moore (Ed.) Handbook of Distance Education. (p. 129-144). Mahwah, NJ.: Erlbaum.

Archer, W., Garrison, D. R., and Anderson, T. (1999). Adopting disruptive technologies in traditional universities: Continuing education as an incubator for innovation. Canadian Journal for University Continuing Education 25(1), 13 - 30. Retrieved July 15, 2003 from: http://www.extension.usask.ca/cjuce/articles/v25pdf/2511.pdf

Bates, A. (1990). Interactivity as a Criterion for Media Selection in Distance Education. Annual Conference of the Asian Association of Open Universities. ERIC Document No. ED329245

Berners-Lee, T. (1998). Realizing the Full Potential of the Web. World-Wide Web Consortium. Retrieved April 3, 2003 from: http://www.w3.org/1998/02/Potential.html

Berners-Lee, T. (1999). Weaving the Web: The original design and ultimate destiny of the World Wide Web by its inventor. San Francisco: Harper.

Clark, R. E. (1994). Media will never influence learning. Educational Technology Research and Development, 42(2), 21 - 29.

Coldeway, D. (1991). Patterns of behaviour in individualized distance education courses. Research in Distance Education, 3(4), 6 - 10.

Collis, B., and Moonen, J. (2001). Flexible learning in a digital world. London: Kogan Page. 
Corbin, J., and Strauss, A. (1990). Grounded Theory Research: Procedures, canons, and evaluative criteria. Qualitative Sociology, 13, 3 - 21.

Daniel, J., and Marquis, C. (1979). Interaction and Independence: Getting the mixture right. Teaching at a Distance, 15, 25 - 44.

Daniel, J., and Marquis, C. (1988). Interaction and independence: Getting the mix right. In D. Sewart, D. Keegan and B. Holmberg (Eds.) Distance Education: International perspectives. (p. 339-359). London: Routledge.

Dewey, J. (1916). Democracy and Education. New York: Macmillan. Retrieved May 21, 2001 from: http://www.ilt.columbia.edu/projects/digitexts/dewey/d_e/contents.html

Fulford, C. P., and Zhang, S. (1993). Perceptions of Interaction: The critical predictor in distance education. American Journal of Distance Education, 7(3), 8 - 21.

Garrison, D. R., and Shale, D. (1990). A new framework and perspective. In D. R. Garrison and D. Shale (Eds.), Education at a distance: from issues to practice. (p. 123-133). Malabar, FL.: Krieger.

Garrison, D. R. (2000). Theoretical challenges for distance education in the 21st century: A shift from structural to transactional issues. International Review of Research in Open and Distance Learning, 1(1) Retrieved May 21, 2001 from: http://www.irrodl.org/content/v1.1/randy.pdf

Garrison, R., Anderson, T., and Archer, W. (2000). Critical thinking in a text-based environment: Computer conferencing in higher education. The Internet and Higher Education 2(2), 87 - 105. Retrieved July 15, 2003 from: http://www.atl.ualberta.ca/cmc/CTinTextEnvFinal.pdf

Garrison, D. R., Anderson, T., and Archer, W. (2000). Critical Thinking and Computer Conferencing: A model and tool to assess cognitive presence. Retrieved July 15, 2003 from: www.atl.ualberta.ca/cmc/CogPresPaper_June30_.pdf

Greer, J., McCalla, G., Vassileva, J., Deters, R., Bull, S., and Kettel, L. (2001). Lessons learned in deploying a multi-agent learning support system: The I-Help experience. AIED. Retrieved April 2, 2003 from: http://julita.usask.ca/Texte/Aied01-camera.pdf

Holmberg, B. (1989). Theory and practice of distance education. London: Routledge.

Jaspers, F. (1991). Interactivity or Instruction? A reaction to Merrill. Educational Technology, 31(3), $21-24$.

Jonassen, D. (1991). Evaluating constructivistic learning. Educational Technology, 31(10), 28 33.

Juler, P. (1990). Promoting interaction; maintaining independence: Swallowing the mixture. Open Learning, 5(2), $24-33$. 
Kirby, D., and Boak, C. (1987). Developing a system for audio-teleconferencing analysis. Journal of Distance Education, 2(2), 31 - 42.

Kirkup, G., and von Prummer, C. (1990). Support and Connectedness: The needs of women distance education students. Journal of Distance Education, 5(2), 9 - 31. Retrieved April 12, 2003 from: http://cade.athabascau.ca/vol5.2/7_kirkup_and_von_prummer.html

Kozma, R. (1994). Will Media Influence Learning? Reframing the debate. Educational Technology Research \& Development, 42(2), 7 - 19.

Kramarae, C. (2003). Gender equity online, when there is no door to knock on. In D. Moore and W. Anderson (Eds.) Handbook of Distance Education. (p. 261-272). Mahwah, NJ.: Lawrence Erlbaum.

Kurzweil, R. (1999). The age of spiritual machines. New York: Penguin Group.

Langer, E. (1989). Mindfulness. Reading, MA.: Addison-Wesley.

Laurillard, D. (1997). Rethinking university teaching: A framework for the effective use of educational technology. London: Routledge.

Lipman, M. (1991). Thinking in Education. Cambridge, UK.: Cambridge University Press.

Litzinger, M. E., Carr, A. A., and Marra, R. (1997). Constructivism, Feminism, and Systemic Change: Finding Common Ground. Presented at the Annual Conference of the Association of Educational Communications and Technology, Albuquerque, NM.

May, S. (1993). Collaborative Learning: More is not necessarily better. American Journal of Distance Education, 7(3), 39 - 49.

McCrosky, J., and Richmond, V. P. (1992). Increasing teacher influence through immediacy. In Richmond V. P. and J. McCrosky (Eds.) Power in the Classroom: Communication, control, and concern. (p. 200-211).

Moore, M. (1989). Three types of interaction. American Journal of Distance Education, 3(2), 1 6.

Parker, L., and Olgren C. (1980). Teleconferencing and interactive media. Madison, WI.: University of Wisconsin Extension Press.

Potter, J. (1998). Beyond Access: Student perspective on support service needs in distance education. The Canadian Journal of University Continuing Education/Revue canadienne de l'éducation permanante universitaire, 24(1) Retrieved October 15, 2002 from: http://www.extension.usask.ca/cjuce/articles/v24pdf/2413.pdf

Roberts, J. (1998). Compressed Video Learning: Creating active learners. Montreal: Cheneliere/McGraw-Hill. 
Rourke, L., Anderson, T., Garrison, D. R., and Archer, W. (2001). Methodolgical issues in the content analysis of computer conference transcripts. International Journal of Artificial Intelligence in Education 12. Retrieved July 15, 2003 from: http://www.atl.ualberta.ca/cmc/2Rourke_et_al_Content_Analysis.pdf

Rourke, L., and Anderson, T. (2002). Using peer teams to lead online discussions. Journal of Interactive Media in Education 1. Retrieved July 15, 2003 from: http://wwwjime.open.ac.uk/2002/1/rourke-anderson-02-1-01.html

Russell, T. (2000). The No Significant Difference Phenomenon. Retrieved Nov. 22, 2000 from: http://cuda.teleeducation.nb.ca/nosignificantdifference/

Saba, F., and Shearer, R. (1994). Verifying key theoretical concepts in a dynamic model of distance education. American Journal of Distance Education, 8(1), 36 - 59.

Seels, B. (1997). Theory development in educational/instructional technology. Education Technology, 37(1), $3-5$.

Sims, R. (1999). Interactivity on stage: Strategies for learner-designer communication. Australian Journal of Educational Technology, 15(3), 257 - 272. Retrieved May 25, 2002 from: http://cleo.murdoch.edu.au/ajet/ajet15/sims.html

Slavin, R. (1995). Cooperative learning theory, research, and practice. Boston: Allyn and Bacon.

Sutton, L. (2001). The principles of vicarious interaction in computer-mediated communications. Journal of Interactive Educational Communications, 7(3), 223 - 242. Retrieved July 15, 2003 from: http://www.eas.asu.edu/elearn/research/suttonnew.pdf

Turoff, M. (1997). Alternative futures for distance learning: The force and the darkside. Virtual Learning Environments and the Role of the Teacher. UNESCO/Open University. Retrieved April 2, 2003 from: http://eies.njit.edu/ turoff/Papers/darkaln.html

Wagner, E.D. (1994). In support of a functional definition of interaction. American Journal of Distance Education, 8(2), 6 - 26.

Wenger, E. (2001). Supporting communities of practice: A survey of community-orientated technologies. (1.3 Ed.) Shareware. Retrieved Mar 12, 2003 from: http://www.ewenger.com/tech/

Wilson, B. (1997). Thoughts on theory in educational technology. Educational Technology, 37(1), $22-26$.

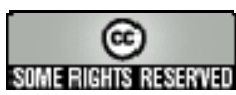

